FEDERAL RESERVE BANK OF SAN FRANCISCO

WORKING PAPER SERIES

\title{
The Economic Status of People with Disabilities and their Families since the Great Recession
}

\author{
Leila Bengali \\ UCLA Anderson School of Management \\ Mary C. Daly \\ Federal Reserve Bank of San Francisco \\ Olivia Lofton \\ Federal Reserve Bank of San Francisco \\ Robert G. Valletta \\ Federal Reserve Bank of San Francisco
}

February 2021

Working Paper 2021-05

https://www.frbsf.org/economic-research/publications/working-papers/2021/05/

\section{Suggested citation:}

Bengali, Leila, Mary C. Daly, Olivia Lofton, Robert G. Valletta. "The Economic Status of People with Disabilities and their Families since the Great Recession," Federal Reserve Bank of San Francisco Working Paper 2021-05.

https://doi.org/10.24148/wp2021-05

The views in this paper are solely the responsibility of the authors and should not be interpreted as reflecting the views of the Federal Reserve Bank of San Francisco or the Board of Governors of the Federal Reserve System. 


\title{
The Economic Status of People with Disabilities and their Families since the Great Recession
}

\author{
Leila Bengali \\ UCLA Anderson School of Management \\ 110 Westwood Plaza \\ Los Angeles, CA 90095-1481 \\ leila.bengali@anderson.ucla.edu \\ Mary C. Daly* \\ Federal Reserve Bank of San Francisco \\ 101 Market Street \\ San Francisco, CA 94105 \\ Mary.Daly@sf.frb.org \\ Olivia Lofton \\ Federal Reserve Bank of San Francisco \\ 101 Market Street \\ San Francisco, CA 94105 \\ Olivia.Lofton@sf.frb.org \\ Robert G. Valletta \\ Federal Reserve Bank of San Francisco \\ 101 Market Street \\ San Francisco, CA 94105 \\ rob.valletta@sf.frb.org
}

First version: December 18, 2020

Revised: February 25, 2021

\begin{abstract}
*Corresponding author: Mary C. Daly. This paper was written for a forthcoming volume of The Annals of the American Association of Political and Social Science, "What has happened to the American Working Class since the Great Recession?," edited by Timothy Smeeding, Michael Strain, and Jennifer Romich. The views expressed in this paper are solely those of the authors and are not attributable to the UCLA Anderson Forecast, the Federal Reserve Bank of San Francisco, or the Federal Reserve System.
\end{abstract}




\title{
The Economic Status of People with Disabilities and their Families since the Great Recession
}

\begin{abstract}
$\underline{\text { Abstract }}$
People with disabilities face substantial barriers to sustained employment and stable, adequate income. We assess how they and their families fared during the long economic expansion that followed the Great Recession of 2007-09, using data from the monthly Current Population Survey (CPS) and the March CPS annual income supplement. We find that the expansion bolstered the well-being of people with disabilities and in particular their relative labor market engagement. We also find that applications and awards for federal disability benefits fell during the expansion. On balance, our results suggest that sustained economic growth can bolster the labor market engagement of people with disabilities and potentially reduce their reliance on disability benefits.
\end{abstract}

Keywords: Disability, employment, income, program participation JEL codes: J14, J11, J18 


\section{The Economic Status of People with Disabilities and their Families since the Great Recession}

\section{Introduction}

People with disabilities face significant barriers to sustained employment and stable, adequate income. Severe physical or cognitive impairments often prevent work and can lead to persistent or permanent receipt of government assistance via disability benefit programs. Less severe impairments may not completely preclude work but nonetheless sharply limit it. As such, people with disabilities often struggle to maintain labor market engagement and obtain adequate incomes for themselves and their families. In other words, people with disabilities face challenges to leading comfortable "working class" lives.

In this paper, we examine the economic status of people with disabilities since the Great Recession of 2007-09. We focus in particular on whether their relative economic status and labor market engagement improved during the unusually long expansion and historically tight labor market reached near its end, as has been found for other disadvantaged groups, though not all (Aaronson et al. 2019, Akee 2021, Finlay and Mueller-Smith 2021). Trends and cyclical patterns in the status of people with disabilities are important in part because of the costs of federal disability benefit programs. Past research suggests that rising incidence of disability claims in prior decades reflects adverse labor market developments and the rising value of disability payments relative to wages (Case and Deaton 2015, Autor and Duggan 2003). Declining disability benefit claims and program participation in recent years suggest that this trend may have been offset or reversed by the long expansion.

We conduct our analyses using data on self-reported disability status from the monthly Current Population Survey (CPS) and the CPS ASEC annual income supplement. We also use 
administrative data on applications and awards for receipt of federal disability benefits, specifically Social Security Disability Insurance benefits (SSDI) and Supplemental Security Income (SSI).

Our results indicate that the overall well-being of people with disabilities improved substantially during the most recent economic expansion (as suggested in Shambaugh and Strain 2021), particularly by comparison with their more limited gains during the 1990s expansion. Our analyses of state panel data indicate that strong labor market conditions that lead to increases in overall labor force participation substantially bolster labor market engagement for people with disabilities relative to those without. We also examine applications and awards for receipt of federal disability benefits and find that they respond to changes in aggregate economic conditions but show somewhat less responsiveness to changes in economic conditions at the state level.

The monthly CPS data currently extend through late 2020 and hence enable a partial, initial assessment of the effects of the COVID-19 pandemic and recession on people with disabilities. The crisis to date has not undermined the relative labor market engagement of people with disabilities, and we do not observe increased applications for disability claims, though processing delays could be a key explanation.

\section{Disability Definitions and Trends}

\section{A. CPS Disability Data}

To conduct our analysis of self-reported disability, we use microdata from the Basic Monthly Current Population Survey (CPS), the source of U.S. official household labor force statistics. The CPS collects a host of labor force and demographic data. To focus on disability 
during prime working years, we restrict our CPS analyses to individuals between 25 and 61 years of age. This represents a slight expansion of the conventional prime-age range of 25 to 54 years of age, thereby incorporating more individuals who report disability late in their working lives but whose employment choices are not directly affected by eligibility for conventional Social Security retirement benefits.

Our primary measure of disability is constructed using self-reported status from the CPS six-question disability sequence. Collected consistently since mid-2008, the six-question sequence is a series of disability-related questions that is posed to all survey respondents when they enter their 4-month CPS sample rotations. Following standard practice, we identify respondents as people with disabilities when they answer "yes" to at least one of the six questions from the sequence.

As a second measure of disability, since 1981 the March CPS survey has included a question about work-limiting disabilities for all household members. We rely less heavily on this measure because in 2015 the wording of the question shifted from current disability status to disability experienced at any time in the prior year, creating a sharp, discontinuous increase in reported disability midway through our analytical timeframe. We therefore use the 6-question sequence to identify people with disabilities in the main analysis. However, we use the work limitation question for supplemental analyses of disability patterns in the 1990s, as discussed in the next section. ${ }^{1}$

To measure economic well-being, we use detailed earnings and income data from the CPS Annual and Social Economic Supplement (ASEC), a supplement administered along with

\footnotetext{
${ }^{1}$ Burkhauser, Houtenville, and Tennant (2013) provide a useful assessment of alternative disability measures in CPS data and related sources.
} 
the basic monthly survey in March and adjacent months. The ASEC asks respondents what their earnings and income were during the prior calendar year, so our earnings and income tabulations refer to the prior year rather than the survey year.

Figure 1 displays disability incidence based on the measures discussed above. Panel A compares the incidence of disability based on the monthly CPS six-question measure and the prior ("traditional") and current work-limitation measures in the ASEC (all calculated from the March survey data). Self-reported disability ranges from about seven to ten percent of the population age 25 to 61 , depending on the specific measure and year. The re-designed ASEC work-limitation measure, based on disability status in the preceding calendar year, yields higher rates of self-reported disability than did the earlier ASEC measure or the six-question sequence, which both reflect disability status at the time of the survey. Compared with other sources, disability incidence measured in the CPS tends to be lower than in panel surveys such as the Panel Study of Income Dynamics (PSID) and the Survey of Income and Program (Meyer and Mok 2019). ${ }^{2}$ However, self-reported disability in the CPS generally exceeds disability incidence as measured by beneficiary counts for the SSDI and SSI programs. ${ }^{3}$

Panel A of Figure 1 also shows that disability incidence calculated from the six-question sequence and traditional work limitation measures diverged during the early part of the recovery from the Great Recession, with little change for the former and an increase for the latter.

\footnotetext{
${ }^{2}$ For their PSID sample of male household heads age 22-61, Meyer and Mok (2019) found self-reported disability incidence that was generally in the range of 12 to 15 percent for years that overlap with our sample period.

${ }^{3}$ This is one implication of the measurement issues discussed in Burkhauser, Houtenville, and Tennant (2013). Beneficiary counts for the SSDI and SSI programs are available on the Social Security Administration website: https://www.ssa.gov/policy/docs/quickfacts/stat snapshot/. The figures for December 2020 imply that less than 5 percent of the population under age 65 receives SSDI or SSI benefits.
} 
However, both the six-question measure and the re-designed work limitation measure show a decline in disability incidence after 2014 , as the economic expansion gained momentum and the labor market tightened. This pattern raises the possibility that self-reported disability status responds to economic conditions. Note however that the decline continued in 2020, when the labor market weakened substantially due to the COVID-19 pandemic. The ongoing decline in self-reported disability is even more apparent in Panel B of Figure 1, which displays disability incidence calculated from annual averages of the twelve monthly surveys (rather than just the March survey as in Panel A). Other factors beyond economic conditions may be contributing to the recent decline in reported disability_for example, the recent easing of the U.S. opioid epidemic (Currie and Schwandt 2021), which may reduce self-reported disability associated with opioid dependence.

\section{B. Trends in Relative Economic Status of people with disabilities}

We now turn to a comparison of economic status indicators between people with disabilities and people without disabilities.

It is important to note first that although individuals with disabilities have low employment rates, their broader economic status tends to place them among the working class according to common definitions. For example, large fractions of our samples of individuals with disabilities lack a college education and are in the bottom half of the distribution of household income. For this reason, and to maintain acceptably large sample sizes for our analyses, we do not trim our sample to conduct analyses based on a specific definition of the working class.

Table 1 lists a set of key indicators of employment status and well-being for the years 2009 and 2019, along with the change between those two years, for people with disabilities and people without disabilities age 25-61. The long expansion following the Great Recession 
produced substantial benefits for people with disabilities and people without disabilities alike. For both groups, the employment to population ratio rose meaningfully, the unemployment rate dropped sharply, and individual earnings and family income rose substantially in real terms. The improvements were generally similar for the two groups. The exception is mean earnings when non-earners are included. When non-earners are excluded, mean earnings are similar for the two groups, which suggests that people without disabilities entered the earnings sample at the lower end of the earnings distribution. This is confirmed by the greater gains for people with disabilities at the $10^{\text {th }}$ and $25^{\text {th }}$ percentiles of earnings relative to people without disabilities.

While Table 1 shows similar gains for people with disabilities and people without disabilities over the past decade, it reveals nothing about the pattern of changes within those timeframes. Those patterns are displayed for selected indicators in Figures 2 and 3. ${ }^{4}$ The labor force, earnings, and income series displayed generally show either steady gains or stagnation followed by a pronounced pickup starting around 2014. These patterns are similar for people with disabilities and people without disabilities. Also, Figure 2 shows no deterioration in the relative employment and unemployment rates of people with disabilities in 2020, despite the severely adverse impact of the COVID-19 pandemic on labor market conditions and general well-being. ${ }^{5}$

It is informative to compare the experience of people with disabilities during the recent expansion to their experience during the 1990s expansion, which was nearly as long as the more recent expansion and produced a similarly tight labor market. Accordingly, Table A1 in the

\footnotetext{
${ }^{4}$ Figures for the remaining indicators in Table 1 are in a supplemental appendix available from the authors.

${ }^{5}$ This visual impression is confirmed by calculations using the exact numbers underlying the series displayed in the two panels of Figure 2.
} 
included appendix reproduces Table 1 for the period 1991-2000, using the work limitation measure available in the ASEC during that period. ${ }^{6}$ The table shows that people with disabilities generally fared poorly during the 1990s, particularly by comparison with the solid improvements enjoyed by people without disabilities. A more detailed comparison of the two periods is beyond the scope of this paper. However, earlier research documented the limited gains for people with disabilities in the 1990s and attributed it in part to the restraining impact of the 1990 Americans with Disabilities Act (ADA) on employers' willingness to hire people with disabilities, along with rapid expansion of the SSDI program during that decade (Burkhauser, Daly, and Houtenville 2001, Acemoglu and Angrist 2001, Autor and Duggan 2003). By contrast, our finding of substantial gains for people with disabilities during the past decade is consistent with recent findings for other disadvantaged groups. ${ }^{7}$

\section{Cyclical Patterns in Disability Status and Employment/Income}

The descriptive time-series evidence discussed in the prior section is suggestive but not definitive regarding cyclical effects on the relative economic status of people with disabilities. To conduct more formal analyses, we formed a state-by-year panel data set for the 50 states plus the District of Columbia, which provides substantial additional variation in economic conditions that we can leverage for estimation. ${ }^{8}$ This data set includes annual observations for the years 2009-2019, using the complete set of 12 monthly CPS files for disability incidence and labor

\footnotetext{
${ }^{6}$ The changes measured in the 1990s are not exactly comparable to those measured for the past decade, due to the change in disability measurement discussed above. However, the 1990s data enable a rough comparison of the gains for people with disabilities during these two periods.

${ }^{7}$ Petrosky-Nadeau and Valletta (2019) found that job-finding rates for racial and ethnic minorities reached unusually high levels near the end of the most recent expansion.

${ }^{8}$ We calculated state/annual means by averaging individual observations within states using the labor force weights in the basic monthly CPS and the annual supplement weights for the CPS ASEC.
} 
force statistics and the CPS ASEC for annual earnings and income data (income data for 2020 were not available at the time this paper was completed).

To get a sense of the variation in the data, Figure 4 shows scatter plots for the relationship in 2019 between state unemployment rates and: (i) disability incidence in Panel A; (ii) the employment-to-population ratio of people with disabilities relative to people without disabilities in Panel B. ${ }^{9}$ As indicated by the fitted lines, disability incidence is higher and relative employment of people with disabilities is lower in states with higher unemployment rates. The position of individual states is largely mirrored in the two panels of Figure 4. For example, high unemployment states such as West Virginia and Mississippi also tend to have high incidence of disability and low relative employment rates for people with disabilities, with the opposite pattern evident for low unemployment rate states such as Colorado and Virginia.

For more formal results, we estimate regressions of the following form, using our state panel data:

$$
Y_{s t}=\alpha+L_{s t} \beta+X_{s t} \gamma+\varphi_{s}+\delta_{t}+\epsilon_{s t}
$$

where $Y$ represents the dependent variables described below, and $s$ and $t$ index state and time (year). ${ }^{10}$

\footnotetext{
${ }^{9}$ The employment-to-population ratio for people with disabilities is substantially lower for people with disabilities in all states and years, hence this ratio of ratios is bounded between 0 and 1 , with a mean value near 0.4 in 2019.

${ }^{10}$ Because our primary dependent variables are measured as fractions and take values close to zero but bounded above it, we use the fractional regression methods developed in Papke and Wooldridge (1996, 2008). Coefficients are reported as average marginal effects; we also measure the key explanatory variables as fractions, so that the coefficients can be interpreted as the percentage point (fractional) change in the outcome per percentage point (fractional) change in the explanatory variables. We report Rsquares calculated directly as the square of the covariance between actual and fitted values of the dependent variable. Observations are weighted by each state's average labor force size over the sample
} 
We are primarily interested in the estimated coefficient $\beta$, which reflects the effects of alternative measures of state labor market conditions $(L)$ as described below. We also account for a set of other relevant time-varying state variables $\left(X_{s t}\right)$, specifically a vector of age-by-gender population shares. ${ }^{11}$ We include state fixed effects $\left(\varphi_{s}\right)$ in selected specifications as discussed below, and all specifications include a complete set of year indicators $\left(\delta_{t}\right)$.

Table 2 reports regression results for the estimated cyclical effect $\beta$. Following Figure 4, Panel A uses the state unemployment rate as the measure of cyclical labor market conditions or slack. The 2019 cross-section regression results in columns 1 and 4 confirm the patterns evident in Figure 4. The average marginal effects indicate large impacts of differences in state unemployment rates on disability incidence and relative employment rates for people with disabilities. The estimate in the first column of Panel A indicates that disability incidence varies across states essentially in tandem with unemployment rates. The estimate in column 4 indicates that relative employment rates of people with disabilities are higher by nearly three percentage points for each percentage point reduction in the unemployment rate; this is a large effect but plausible by comparison with the wide variation in relative employment rates for people with disabilities in our sample. ${ }^{12}$ These estimated effects are qualitatively similar but substantially smaller in magnitude for the full panel specification in columns 2 and 5, and they are quite small and statistically insignificant in the specifications that include state fixed effects (columns 3 and

period, and the standard errors are clustered by state. See Valletta, Bengali, and van der List (2020) for additional details of the general estimation approach and reported statistics.

${ }^{11}$ The age groups are 16-24, 25-34, 35-54, 55-64, and 65 and over. These variables are included to account for demographic features of each state that change over time and may affect overall disability incidence within the state.

${ }^{12}$ The standard deviations for the unemployment rate and relative employment measure are about 0.6 and 6 percentage points in the 2019 cross-section and about 2.5 and 7 percentage points in the complete 200919 panel. 
6). The reduced size of the estimates in the full panel compared with the 2019 cross-section suggests that persistent unmeasured features of state economies and populations cause states with high unemployment rates to also have high disability incidence and low relative employment rates for people with disabilities.

Given the sharp decline in labor force participation (LFP) during the Great Recession and subsequent slow recovery, LFP may be a better indicator of labor market strength or slack than the unemployment rate (Faberman et al. 2020). In Panel B of Table 2, we therefore replace the unemployment rate with the state labor force participation rate (age 16 and over). As expected, the LFP variable produces opposite signed coefficients relative to the unemployment variables, because high LFP (unemployment) indicates a strong (weak) labor market. Importantly, the estimated coefficient on the LFP variable remains large and statistically precise in the column 6 regression for relative employment rates, which includes state fixed effects. We place greatest emphasis on the fixed-effects specification. In these specifications, the coefficient of interest is likely to reflect a true cyclical relationship rather than underlying state characteristics-e.g., industry and labor force composition or institutional features of state labor markets—-that vary little over time but cause some states to have both weaker labor markets and less favorable outcomes for individuals with disabilities. The estimated effect in column 6 of Panel B (Table 2) is quite large: a one standard deviation difference in the LFP rate over our 2009-19 sample frame (about 3 percentage points) is associated with over a one-half standard deviation difference in the relative employment rate for people with disabilities.

We also estimated the same specification for the broad set of income and earnings variables discussed earlier and listed in Table 1 . We found very little evidence that these 
measures of the relative economic well-being of people with disabilities respond to variation in labor market slack and hence do not list those results here. ${ }^{13}$

Overall, our analyses using state panel data indicate that the labor market engagement of people with disabilities relative to people without disabilities is affected by labor market conditions, particularly labor force participation rates. This likely reflects unique cyclical movements in LFP rates during the most recent business cycle, including a sharp decline and subsequent recovery for prime-age workers, which makes it a useful metric for assessing overall labor market health (Faberman et al. 2020).

\section{Disability Benefit Program Participation}

Bolstering the employment engagement of people with disabilities may reduce their reliance on government disability benefits. In this section, we build on the results in the preceding section by assessing patterns in the use of disability insurance programs (SSDI and SSI) over the past decade.

Social Security Disability Insurance (SSDI) pays benefits to individuals with extensive work histories who develop a severe work-limiting disability. Because SSDI receipt tends to be persistent or permanent, and hence costly, the application process is extensive and often entails lengthy delays. SSDI protection is buttressed by Supplemental Security Income (SSI), which provides payments to lower-income adults and children with disabilities regardless of work history, as well as to lower-income people aged 65 or older, typically on a temporary basis. ${ }^{14}$

\footnotetext{
${ }^{13}$ The results using LFP as the measure of labor market conditions are provided in a supplemental appendix that is available from the authors.

${ }^{14}$ These social insurance programs both offer recipients monthly cash benefits (that depend on prior work history and wages in the case of SSDI) after an applicant has been deemed eligible and meets the Social Security Administration's criteria for having a disability.
} 
The majority of individuals who receive disability insurance benefits are not in the labor force. However, trends in program use are relevant for understanding labor market outcomes for individuals with disabilities because current decisions about disability program use have a large effect on future labor market status and thus economic outcomes: once an individual is awarded a disability benefit, they tend to stay on the program and permanently leave the labor force. ${ }^{15}$ If changes in labor market conditions influence the use of disability insurance programs, a recovery or recession can have lasting impacts on the economic well-being of people with disabilities (see e.g. Maestas, Mullen, and Strand 2015 and 2018, and Stapleton et al. 1998).

One reason that labor market conditions would be expected to affect disability insurance program use is that recessions increase the relative attractiveness of disability insurance relative to the outside option of staying in the labor force. Market wages may fall, and for the unemployed, so does the probability of finding a job. The prediction that an erosion of the outside option encourages disability insurance program use has been documented in a number of studies (see e.g. Autor and Duggan 2003 and Black, Daniel, and Sanders 2002). The pattern of applications to the disability insurance programs over time, shown in Figure 5, fits this story. Applications appear to follow the cyclical pattern in the unemployment rate. ${ }^{16}$

To quantify the relationship between disability insurance program use and labor market cyclicality, we use state-by-month panel data aggregated to an annual frequency. These data are from the Social Security Administration (SSA) and represent state Disability Determination

\footnotetext{
${ }^{15}$ In 2018 , over 85 percent of SSDI program terminations for beneficiaries with disabilities were due to death or to the beneficiary reaching retirement age (and thus transitioning to Social Security).

${ }^{16}$ Though not included in our analysis of the recovery from the 2007 - 2009 recession, applications to SSDI and SSI fell notably in 2020 (Figure 5), despite the onset of a sharp recession. This drop likely due to office closures and processing delays for the programs. Benefit awards for these programs also declined in 2020 .
} 
Service workloads from October 2000 through December 2020. This data set gives applications, determinations, and allowances for the SSDI and SSI programs, and we sum the data across these programs in our analysis. ${ }^{17}$

We use these data to estimate state panel regressions that are identical to those described in the preceding section, but with measures of disability program participation as the dependent variables: specifically, the application rate (applications per 10 people age $25-64)$ and two definitions of awards rate (awards per 10 people age $25-64$, and the number of awards per determination).

Our main results in Table 3 yield two general conclusions: there is some cyclicality in disability insurance program use, and time-invariant differences between states have substantial explanatory power. Generally, our findings are consistent with existing research. The results in the first two columns show that applications for disability insurance tend to rise with unemployment rates (consistent with prior work, such as Maestas, Mullen, and Strand 2015 and 2018). However, adding state fixed effects (column 2) reduces the magnitude of the relationship substantially, an indication of the importance of persistent effects of state labor market or institutional features. We find that a 2.5 percentage point (roughly one standard deviation) difference in state unemployment rates is associated with an increase in the application rate of about 0.013 in column 1 and just under 0.01 when fixed effects are included in column 2 . These are modest effects relative to the mean application rate of about 0.185 and the standard deviation of about 0.058 .

\footnotetext{
${ }^{17}$ There are a few notable limitations with this data set. First, the data do not include applications that were rejected after an initial eligibility screening. Second, claims include workers, spouses, and SSDI child claimants, as opposed to (ideally) just workers. Finally, the data do not include full information about appealed applications that were initially denied, which have been shown to ultimately generate a non-trivial number of awards. See the supplemental appendix for additional details about the data.
} 
Turning to initial awards, we do not find a cyclical pattern in awards as a fraction of the population (despite the aggregate time series in Figure 5 seeming to suggest one). However, we do find that the award rate measured as the number of awards per determination is cyclically sensitive, as also documented in the existing research noted above. ${ }^{18}$ Our results show that a 2.5 percentage point increase in the unemployment rate is associated with about a 0.023 (just over a third of a standard deviation) decline in the award rate (which has a mean of 0.347). This estimate is substantially offset by the inclusion of state fixed effects in column 6 , which reduces the magnitude of the coefficient by more than half and eliminates its statistical significance. These findings are broadly consistent with the interpretation that when labor markets weaken, the marginal applicant is less likely to qualify for disability programs. ${ }^{19}$

Data limitations prevent a comparison to the 1990s expansion, but we can examine these same relationships during the (shorter) expansion that followed the 2001 recession. During this recovery, we find similar but slightly stronger evidence of cyclicality in disability program use (see Table A2 in the included appendix). This suggests that the cyclicality we find in the recovery following the 2007-09 recession likely represents a general relationship between disability program use and labor market conditions rather than unique features of that recovery.

Our findings indicate that applications for disability insurance programs rose during the $2007-2009$ recession. The majority of individuals ultimately awarded benefits likely left the labor market permanently. The permanence of these labor market exits may, in aggregate, limit

\footnotetext{
${ }^{18}$ Using awards per application yields similar results (available in the separate authors' appendix).

${ }^{19}$ These findings are robust to a number of alternative specifications, including using OLS, adding measures of unemployment insurance availability and disability prevalence in the population, removal of regression weights, and using LFP in place of the unemployment rate (in the separate authors' appendix). The results using LFP have coefficients of roughly similar magnitudes, though opposite signs, compared to the statistically significant coefficients in Table 3 . The LFP coefficients are not statistically significant when state fixed effects are included.
} 
the benefits of long economic expansions for people with persistent disabilities: as noted above, once they enter the program, they typically do not exit later.

Regarding the COVID-19 recession, the data through December 2020 show a sharp decline in applications and awards, though this could reflect SSA office closures and backlogs (see the footnoted discussion of Figure 5 above). Simple cross-sectional correlations across all states and months in 2020 are inconclusive, not showing evidence of significant correlations. Whether there will be a rise in applications as a result of the COVID-19 recession is yet to be determined.

\section{Discussion and Conclusions}

Our analyses of the employment and economic status of people with disabilities since the Great Recession yields some encouraging findings. We find consistent and robust evidence that the long labor market expansion, which caused a notable increase in prime-age labor force participation rates in recent years, bolstered the labor force engagement of individuals who selfidentify as having a disability. We also find somewhat weaker evidence that the long expansion led to reduced entry into government disability programs. Combined, these results suggest that sustained economic expansions can help improve the well-being of people with disabilities and reduce their reliance on public support programs. Slower population aging may already be easing the growth in disability benefit rolls (Liebman 2015). Our results suggest that a sustained economic expansion following the COVID-19 crisis could contribute to further improvements in the economic well-being of people with disabilities. 


\section{References}

Aaronson, Stephanie R., Mary C. Daly, William L. Wascher, and David W. Wilcox. 2019. "Okun revisited: who benefits most from a strong economy?" Brookings Papers on Economic Activity, 333-375.

Acemoglu, Daron, and Joshua D. Angrist. 2001. "Consequences of employment protection? The case of the Americans with disabilities act." Journal of Political Economy 109(5): 915957.

Akee, Randall. 2021. "Great Recession and American Indian and Alaska Natives and Native Hawaiians and Pacific Islanders." Forthcoming in What has happened to the American Working Class since the Great Recession? (2009-2019), eds. Timothy M. Smeeding, Jennifer Romich, and Michael R. Strain. ANNALS of The American Academy of Political and Social Science.

Autor, David H., and Mark G. Duggan. 2003. "The rise in the disability rolls and the decline in unemployment." The Quarterly Journal of Economics 118 (1): 157-206.

Black, Dan, Kermit Daniel, and Seth Sanders. 2002. "The impact of economic conditions on participation in disability programs: evidence from the coal boom and bust." American Economic Review 92 (1): 27-50.

Burkhauser, Richard V., Mary C. Daly, and Andrew J. Houtenville. 2001. "How Working Age People With Disabilities Fared Over the 1990s Business Cycle." In Ensuring Health and Income Security for an Aging Workforce (pp. 291-346), eds. Peter P. Budetti, Richard V. Burkhauser, Janice M. Gregory, and H. Allan Hunt. Kalamazoo, MI: W.E. Upjohn Institute for Employment Research.

Burkhauser, Richard V., Andrew J. Houtenville, and Jennifer Tennant. 2013. "Measuring the population with disabilities for policy analysis." In Lifecycle events and economic security: the roles of job loss, disability and changing family structure, eds. Kenneth A. Couch, Mary C. Daly, and Julie Zissimopoulos, 215-239. Stanford, CA: Stanford University Press.

Case, A., and A. Deaton. 2015. "Rising morbidity and mortality in midlife among white nonHispanic Americans in the 21st century." Proceedings of the National Academy of Sciences 112 (49): 15078-15083.

Currie, Janet, and Hannes Schwandt. 2021. "The Opioid Epidemic Was Not Caused by Economic Distress But by Factors that Could be More Rapidly Addressed." NBER Working Paper No. 27544, August. Forthcoming in What has happened to the American Working Class since the Great Recession? (2009-2019), eds. Timothy M. Smeeding, Jennifer Romich, and Michael R. Strain. ANNALS of The American Academy of Political and Social Science. 
Faberman, Jason, Andreas I. Mueller, Ayşegül Şahin, and Giorgio Topa. 2020. "The shadow margins of labor market slack." National Bureau of Economic Research Working Paper 26852, Cambridge, MA.

Finlay, Keith, and Michael Mueller-Smith. 2021. "Justice-involved individuals in the labor market since the Great Recession." Forthcoming in What has happened to the American Working Class since the Great Recession? (2009-2019), eds. Timothy M. Smeeding, Jennifer Romich, and Michael R. Strain. ANNALS of The American Academy of Political and Social Science.

Liebman, Jeffrey B. 2015. "Understanding the increase in disability insurance benefit receipt in the United States.” Journal of Economic Perspectives, 29 (2): 123-50.

Maestas, Nicole, Kathleen J. Mullen, and Alexander Strand. 2015. "Disability insurance and the great recession." American Economic Review 105 (5): 177-82.

Maestas, Nicole, Kathleen J. Mullen, and Alexander Strand. 2018. "The effect of economic conditions on the disability insurance program: evidence from the great recession." National Bureau of Economic Research Working Paper 25338, Cambridge, MA.

Meyer, Bruce D., and Wallace K.C. Mok. 2019. "Disability, earnings, income and consumption." Journal of Public Economics 171: 51-69.

Papke, Leslie E., and Jeffrey M. Wooldridge. 1996. "Econometric methods for fractional response variables with an application to 401(k) plan participation rates." Journal of Applied Econometrics 11 (6): 619-632.

Papke, Leslie E., and Jeffrey M. Wooldridge. 2008. "Panel data methods for fractional response variables with an application to test pass rates." Journal of Econometrics 145: 121-33.

Petrosky-Nadeau, Nicolas, and Robert G. Valletta. 2019. "Unemployment: lower for longer?" FRBSF Economic Letter 2019-21.

Shambaugh, Jay C., and Michael R. Strain. 2021. "The recovery from the Great Recession: a long, evolving expansion." Forthcoming in What has happened to the American Working Class since the Great Recession? (2009-2019), eds. Timothy M. Smeeding, Jennifer Romich, and Michael R. Strain. ANNALS of The American Academy of Political and Social Science.

Stapleton, David, Kevin Coleman, Kimberly Dietrich, and Gina Livermore. 1998. "Empirical analyses of DI and SSI application and award growth." In Growth in disability benefits: explanations and policy implications, eds. Kalman Rupp and David C. Stapleton, 31-92. Kalamazoo, MI: W.E. Upjohn Institute for Employment Research.

Valletta, Robert G., Leila Bengali, and Catherine van der List. 2020. Cyclical and market determinants of involuntary part-time employment. Journal of Labor Economics 38 (1): 67-93. 


\section{Figure 1: Disability Incidence in the CPS}

\section{Panel A: Alternative Measures}

\section{Disability Prevalence by Measure}

$10.0 \%$

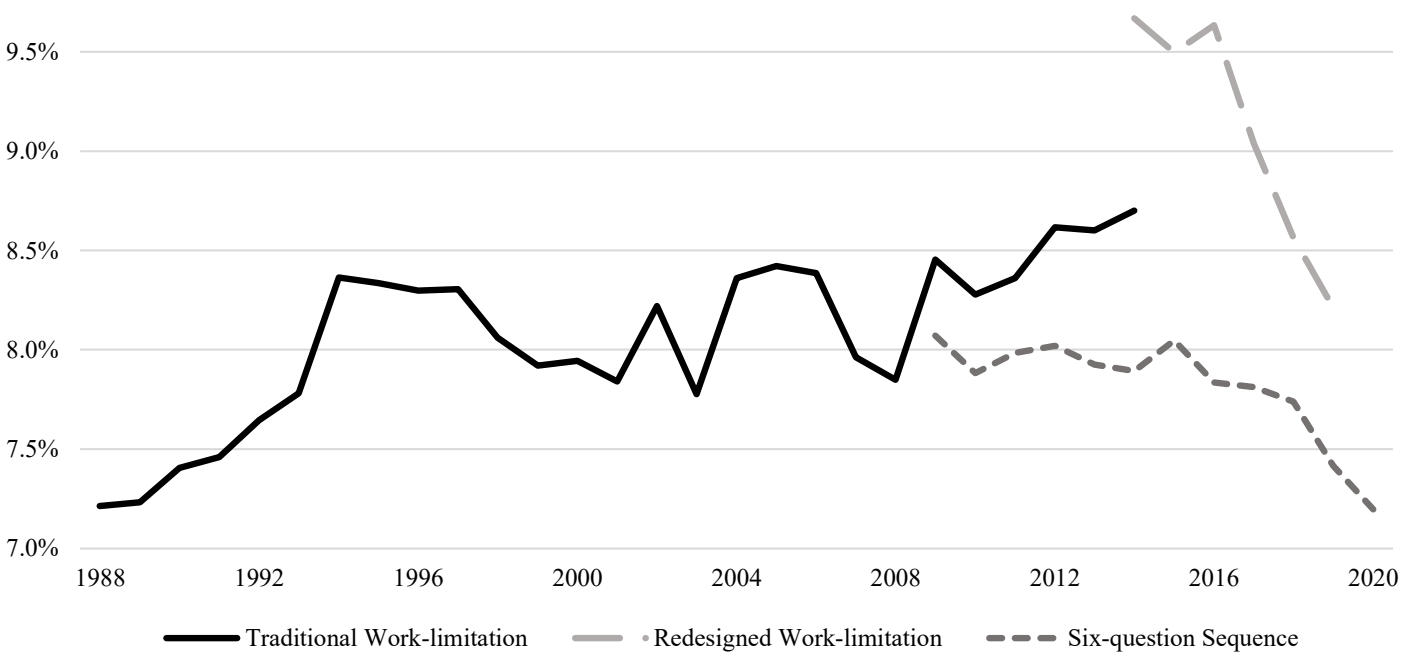

Source: CPS ASEC 1988-2020

Notes: Sample includes all civilians between the ages 25 and 61. Estimates for the redesigned work-limitation measure are

lagged by one survey year in accordance with the question's reference period. Respondents are considered to have a

disability by the six-question sequence measure if they answered "yes" to at least one sequence question.

\section{Panel B: Monthly CPS Six-Question Sequence}

\section{Disability Prevalence}

$8.5 \%$

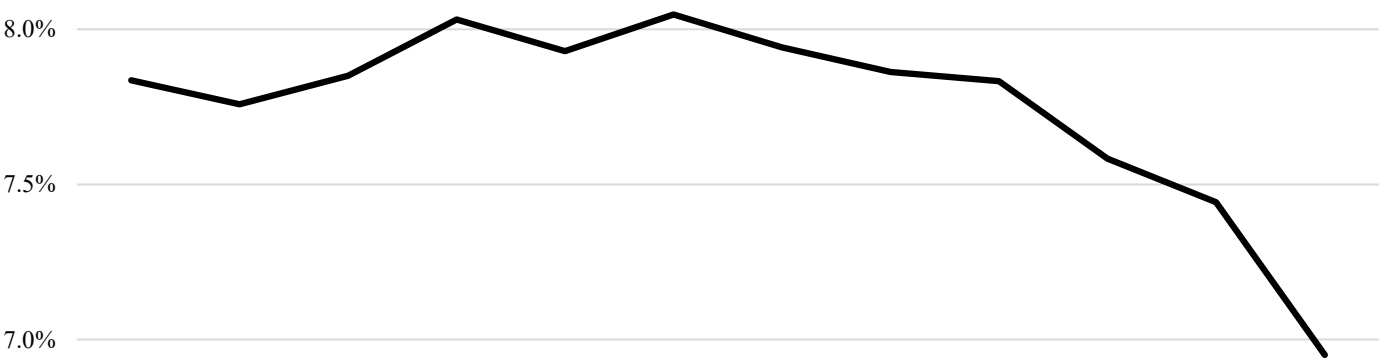

$6.5 \%$

$\begin{array}{llllllllllll}2009 & 2010 & 2011 & 2012 & 2013 & 2014 & 2015 & 2016 & 2017 & 2018 & 2019 & 2020\end{array}$

Source: Basic Monthly CPS 2009-2020

Notes: Sample includes all civilians between the ages 25 and 61. All estimates are weighted annual averages. Values for 2020 based on data for Jan.-Oct. compared with the same period in 2019. The population with disabilities is defined to be all survey respondents who answered "yes" to at least one of six questions from the CPS disability sequence. 
Figure 2: Labor Market Status and Disability

\section{Panel A}

\section{Employment-to-population Ratio by Population}

$100 \%$

$85 \%$

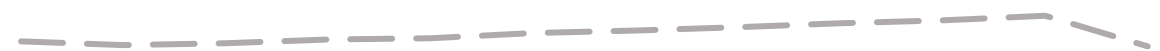

$70 \%$

$55 \%$

$40 \%$

$25 \%$

$10 \%$

\begin{tabular}{|c|c|c|c|c|c|c|c|c|c|c|c|}
\hline 2009 & 2010 & 2011 & 2012 & 2013 & 2014 & 2015 & 2016 & 2017 & 2018 & 2019 & 2020 \\
\hline
\end{tabular}

Source: Basic Monthly CPS 2009-2020

Notes: Sample includes all civilians between the ages 25 and 61 . All estimates are weighted annual averages. Values for

2020 based on data for Jan.-Oct. compared with the same period in 2019. The population with disabilities is defined to be

all survey respondents who answered "yes" to at least one of six questions from the CPS disability sequence.

\section{Panel B}

\section{Unemployment Rate by Population}

$18 \%$

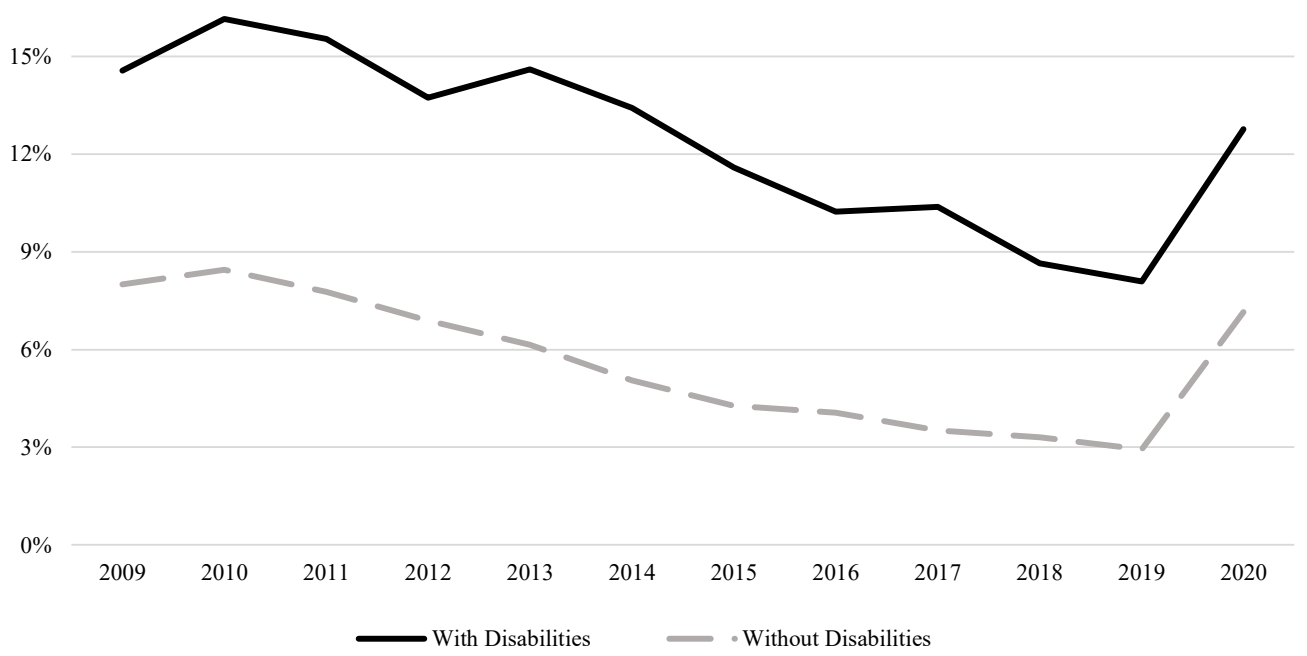

Source: Basic Monthly CPS 2009-2020

Notes: Sample includes all civilians in the labor force between the ages 25 and 61 . Values for 2020 based on data for Jan.-

Oct. compared with the same period in 2019 . The population with disabilities is defined to be all survey respondents who answered "yes" to at least one of six questions from the CPS disability sequence. 
Figure 3: Earnings and Income, by Disability

Panel A: Earnings (positive earners only)

Mean Personal Earnings by Population

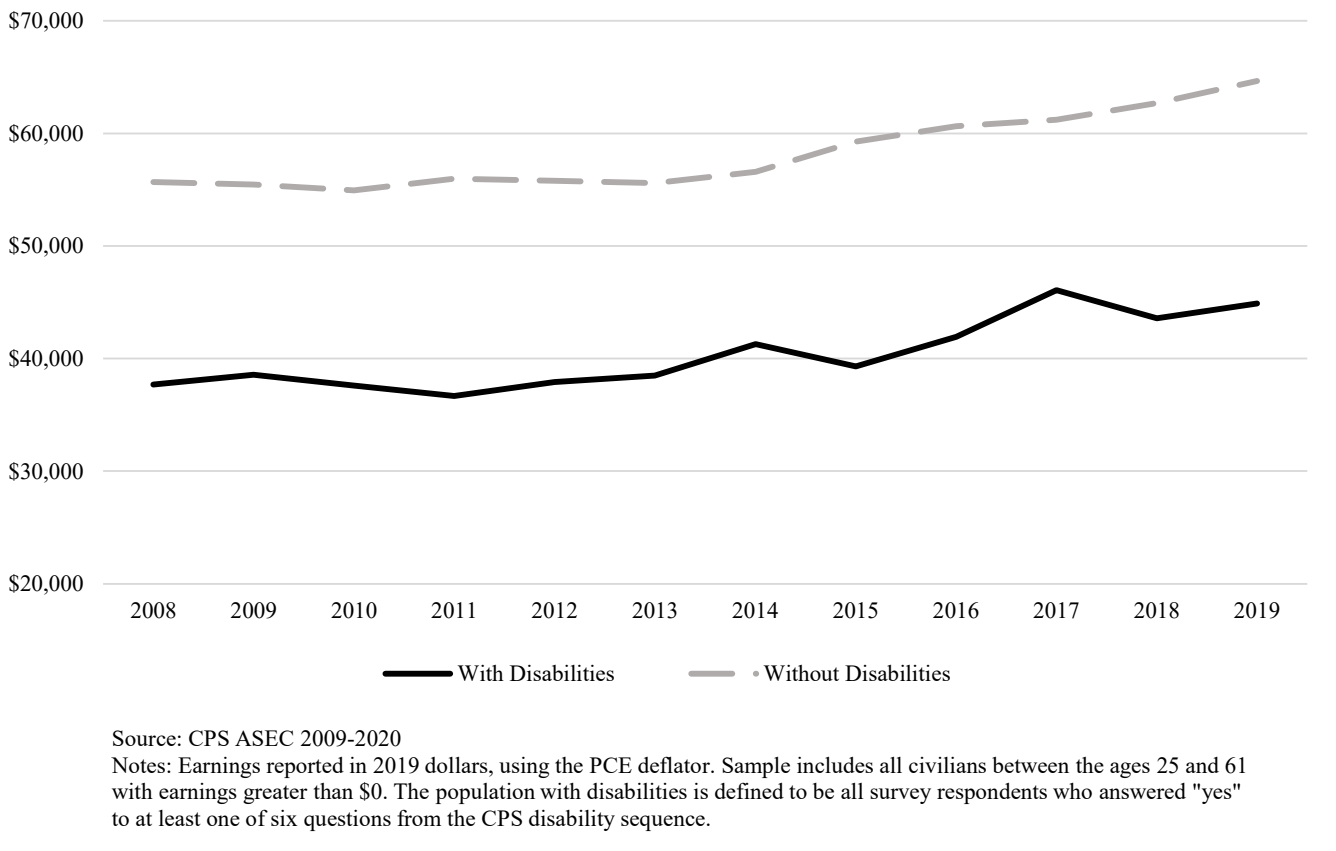

Panel B: Equivalent Family Income

Median Equivalent Household Income by Population

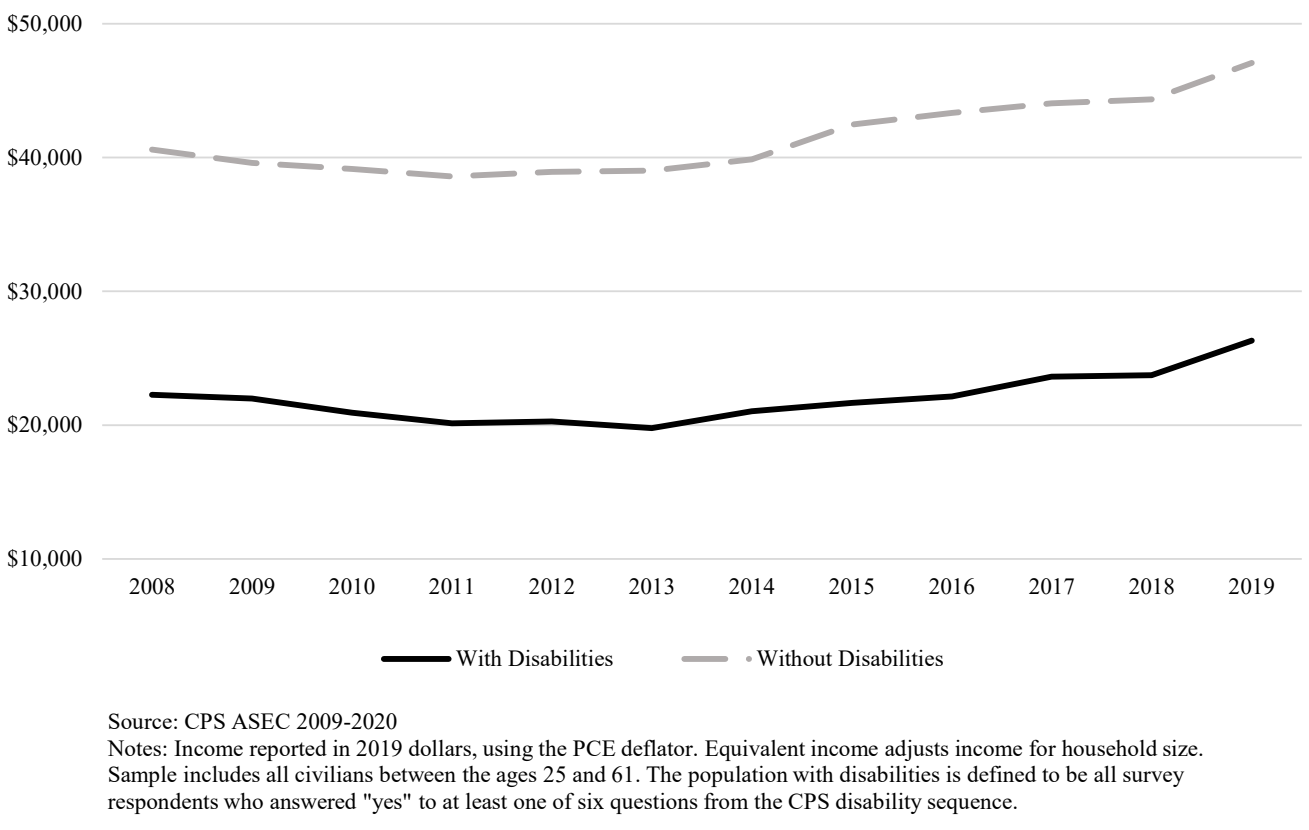


Figure 4: Disability and Employment Ratio vs. Unemployment Rates

Panel A

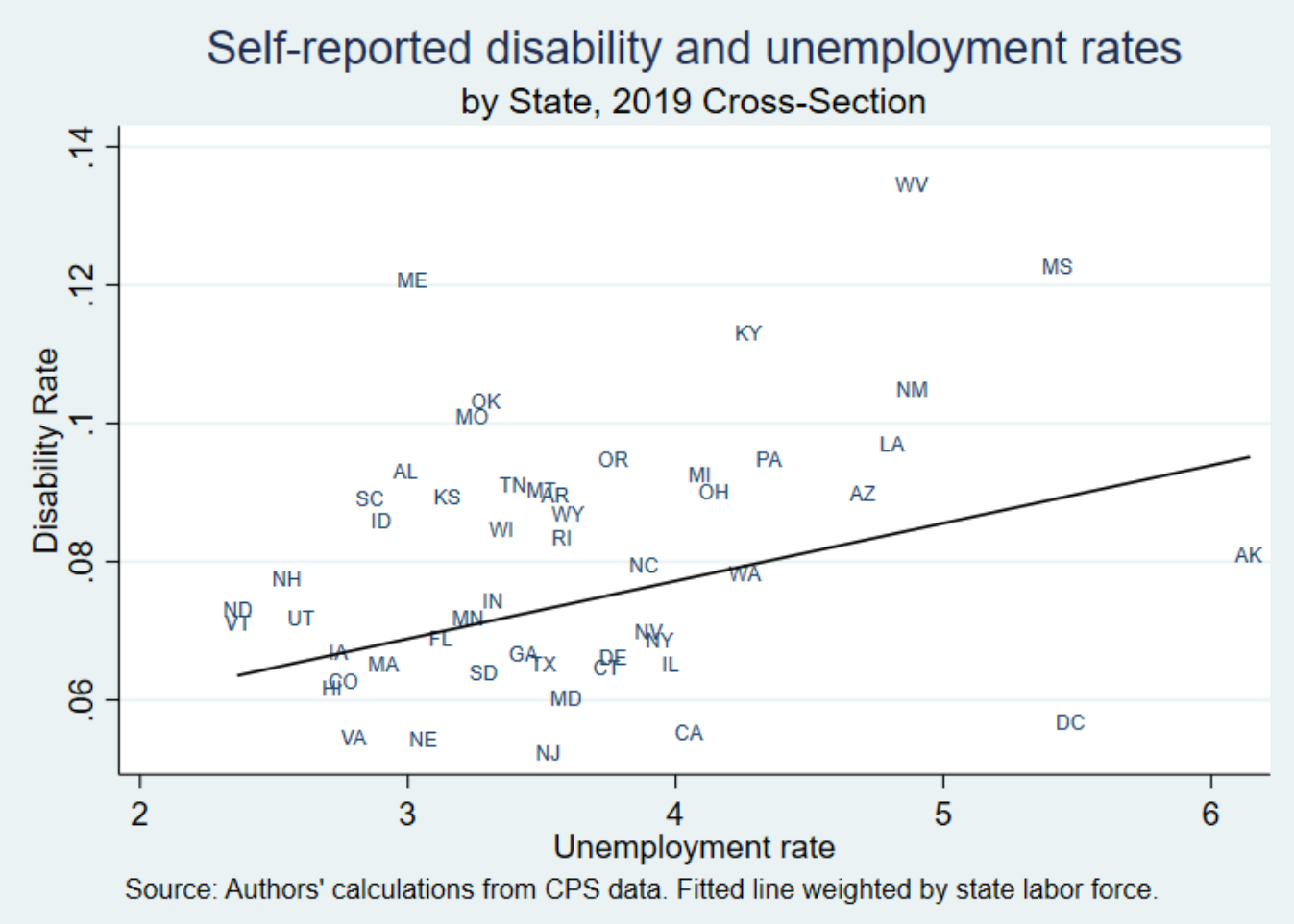

\section{Panel B}

With/without disabilities emp ratio and unemployment rates

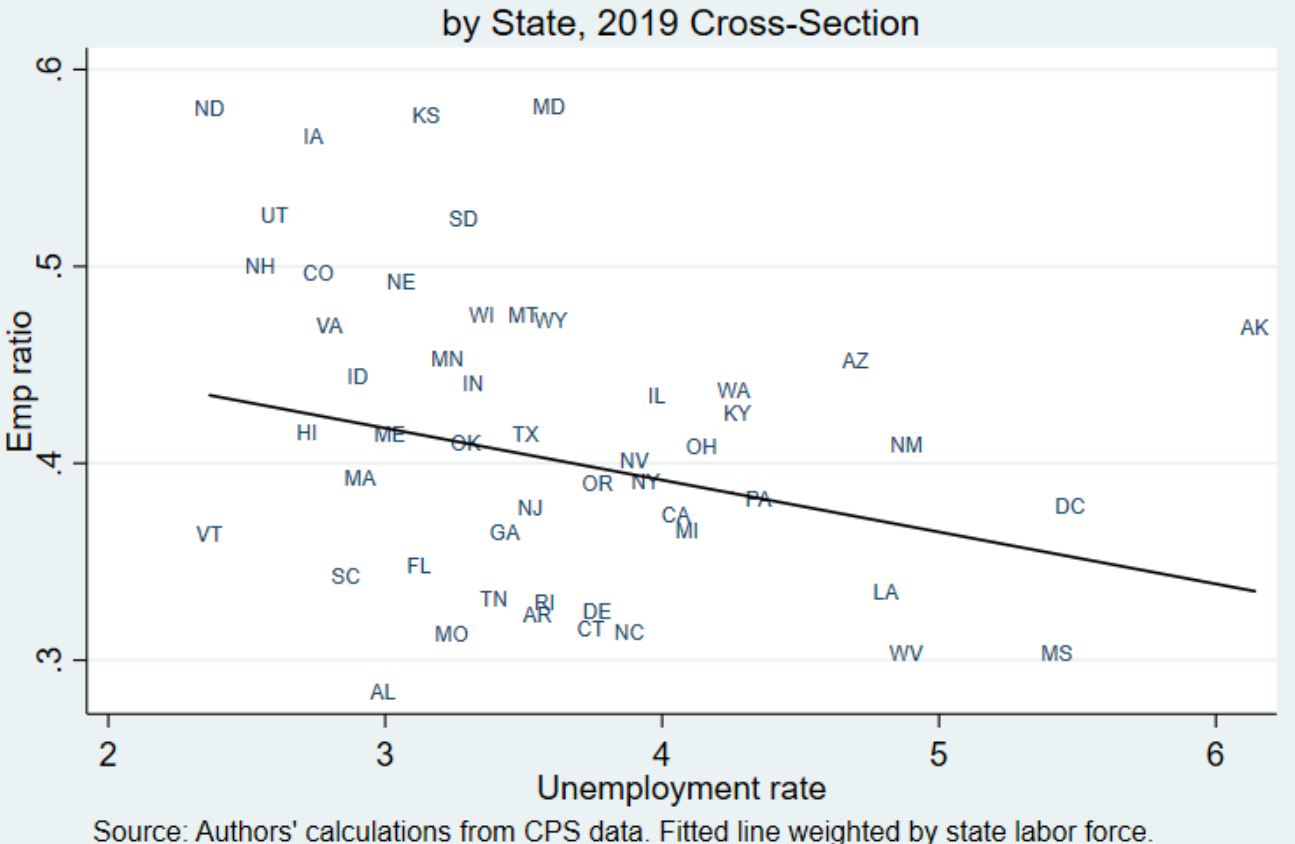


Figure 5

Initial Claims for Disability Insurance

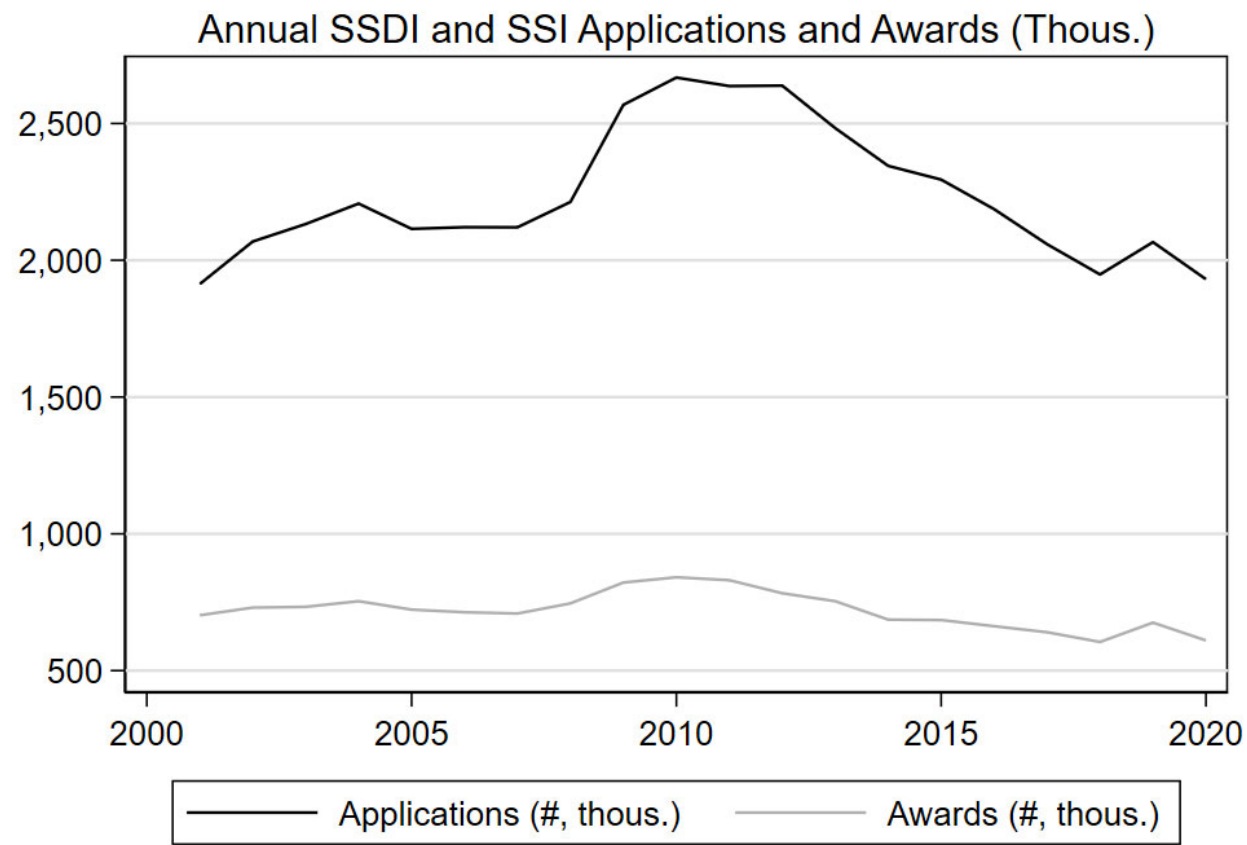

Source: SSA monthly workflow data and Authors' calculations.

Note: Data include SSDI and SSI worker, widow and SSDI child claimants (no

reconsiderations/appeals) from 50 states + DC sent to a state DDS office. 
Table 1

Outcome measures by population, before and after recovery

\begin{tabular}{|c|c|c|c|}
\hline & 2009 & 2019 & Change \\
\hline Disability by Six-question Sequence & $7.84 \%$ & $7.44 \%$ & $-.39 \mathrm{pp}$ \\
\hline \multicolumn{4}{|l|}{ Employment-to-population Ratio } \\
\hline With Disabilities & $31.32 \%$ & $32.41 \%$ & $1.09 \mathrm{pp}$ \\
\hline Without Disabilities & $77.71 \%$ & $81.74 \%$ & $4.03 \mathrm{pp}$ \\
\hline \multicolumn{4}{|l|}{ Unemployment Rate } \\
\hline With Disabilities & $14.57 \%$ & $8.09 \%$ & $-6.48 \mathrm{pp}$ \\
\hline Without Disabilities & $8.00 \%$ & $2.93 \%$ & $-5.07 \mathrm{pp}$ \\
\hline \multicolumn{4}{|l|}{ Individual Earnings } \\
\hline \multicolumn{4}{|l|}{ Including Non-earners } \\
\hline \multicolumn{4}{|l|}{ Mean } \\
\hline With Disabilities & $\$ 14,744$ & $\$ 18,617$ & $26.27 \%$ \\
\hline Without Disabilities & $\$ 45,861$ & $\$ 54,907$ & $19.72 \%$ \\
\hline \multicolumn{4}{|l|}{ Excluding Non-earners } \\
\hline \multicolumn{4}{|l|}{ Mean } \\
\hline With Disabilities & $\$ 38,554$ & $\$ 44,886$ & $16.42 \%$ \\
\hline Without Disabilities & $\$ 55,465$ & $\$ 64,656$ & $16.57 \%$ \\
\hline \multicolumn{4}{|l|}{$10^{\text {th }}$ Percentile } \\
\hline With Disabilities & $\$ 3,853$ & $\$ 5,225$ & $35.62 \%$ \\
\hline Without Disabilities & $\$ 11,675$ & $\$ 15,000$ & $28.48 \%$ \\
\hline \multicolumn{4}{|l|}{$25^{\text {th }}$ Percentile } \\
\hline With Disabilities & $\$ 11,675$ & $\$ 15,000$ & $28.48 \%$ \\
\hline Without Disabilities & $\$ 23,349$ & $\$ 28,000$ & $19.92 \%$ \\
\hline \multicolumn{4}{|l|}{ Household Income } \\
\hline \multicolumn{4}{|l|}{ Mean } \\
\hline With Disabilities & $\$ 57,978$ & $\$ 70,643$ & $21.84 \%$ \\
\hline Without Disabilities & $\$ 100,760$ & $\$ 125,379$ & $24.43 \%$ \\
\hline \multicolumn{4}{|l|}{ Median } \\
\hline With Disabilities & $\$ 40,861$ & $\$ 49,159$ & $20.31 \%$ \\
\hline Without Disabilities & $\$ 79,533$ & $\$ 96,000$ & $20.70 \%$ \\
\hline \multicolumn{4}{|l|}{ Equivalent Household Income } \\
\hline \multicolumn{4}{|l|}{ Mean } \\
\hline With Disabilities & $\$ 31,235$ & $\$ 36,877$ & $18.07 \%$ \\
\hline Without Disabilities & $\$ 50,277$ & $\$ 61,886$ & $23.09 \%$ \\
\hline \multicolumn{4}{|l|}{ Median } \\
\hline With Disabilities & $\$ 21,988$ & $\$ 26,319$ & $19.07 \%$ \\
\hline Without Disabilities & $\$ 39,592$ & $\$ 47,051$ & $18.84 \%$ \\
\hline N (Basic Monthly) & 813,138 & 673,883 & \\
\hline$N($ ASEC) & 102,817 & 74,010 & \\
\hline $\begin{array}{l}\text { Sample includes all civilians between } \\
2020 \text { CPS ASEC and are reported in } 2 \\
\text { averages calculated with the } 2009 \text { and } \\
\text { for household size. Non-earners are de } \\
\text { disabilities includes all respondents wl } \\
\text { sequence. }\end{array}$ & es" to at least $\$$ & $\begin{array}{l}\text { ggs are calcu } \\
\text { All other fig } \\
\text { t household } \\
n \text { earnings. T } \\
x \text { questions }\end{array}$ & $\begin{array}{l}\text { the } 2010 \text { a } \\
\text { ighted ann } \\
\text { usts incom } \\
\text { tion with } \\
\text { PS disabili }\end{array}$ \\
\hline
\end{tabular}


Table 2: Regression results: disability incidence and employment ratio

Panel A

Cyclical control: state unemployment rate

Disability incidence

Disability/non emp ratio

\begin{tabular}{|c|c|c|c|c|c|c|}
\hline & & \\
\hline & (1) & (2) & (3) & (4) & (5) & $(6)$ \\
\hline & & & Fixed & & & Fixed \\
\hline & & Panel & effects & & Panel & effects \\
\hline \multirow{3}{*}{ Unemp rate } & 2019 only & $(2009-19)$ & $(2009-19)$ & 2019 only & $(2009-19)$ & $(2009-19)$ \\
\hline & $1.012 * * *$ & $0.212 * *$ & 0.049 & $-2.702 * *$ & $-1.117 * * *$ & 0.326 \\
\hline & $(0.245)$ & $(0.096)$ & $(0.070)$ & $(1.148)$ & $(0.245)$ & $(0.280)$ \\
\hline State fixed effects & $\mathrm{N}$ & $\mathrm{N}$ & $\mathrm{Y}$ & $\mathrm{N}$ & $\mathrm{N}$ & $\mathrm{Y}$ \\
\hline R-squared & 0.436 & 0.271 & 0.899 & 0.480 & 0.542 & 0.743 \\
\hline $\mathrm{N}$ & 51 & 561 & 561 & 51 & 561 & 561 \\
\hline
\end{tabular}

Note: Fractional regression model results (average marginal effects and standard errors) using the methods of Papke and Wooldridge $(1996,2008)$ and state panel data calculated from CPS microdata, 2009-19. All columns include controls for gender*age population shares and complete year dummies (not shown). Standard errors clustered by state and state labor force values (period average) used as regression weights. Year dummies and clustering not used for 2019 cross-section (columns 1 and 4).

Panel B

Cyclical control: state LFP rate Disability incidence

Disability/non emp ratio

(1)

(2)

(3)

(4)

(5)

(6)

Fixed

Panel effects

Panel effects

2019 only (2009-19) (2009-19) 2019 only (2009-19) (2009-19)

LFP rate

$\begin{array}{llllll}-0.198^{* * *}-0.286^{* * *} & -0.016 & 1.507^{* * *} & 1.096^{* * *} & 1.302 * * *\end{array}$

$\begin{array}{lll}(0.060) & (0.047) \quad(0.057)\end{array}$

(0.357)

$(0.193)$

$(0.414)$

\begin{tabular}{lcccccc} 
State fixed effects & $\mathrm{N}$ & $\mathrm{N}$ & $\mathrm{Y}$ & $\mathrm{N}$ & $\mathrm{N}$ & $\mathrm{Y}$ \\
\hline $\mathrm{R}$-squared & 0.477 & 0.557 & 0.898 & 0.636 & 0.632 & 0.757 \\
$\mathrm{~N}$ & 51 & 561 & 561 & 51 & 561 & 561 \\
\hline
\end{tabular}

$* \mathrm{p}<.10, * * \mathrm{p}<.05, * * * \mathrm{p}<.01$

Note: Fractional regression model results (average marginal effects and standard errors) using the methods of Papke and Wooldridge $(1996,2008)$ and state panel data calculated from CPS microdata, 2009-19. All columns include controls for gender*age population shares and complete year dummies (not shown). Standard errors clustered by state and state labor force values (period average) used as regression weights. Year dummies and clustering not used for 2019 cross-section (columns 1 and 4). 
Table 3: Regression results for disability program applications/awards

\section{Main Results}

\begin{tabular}{|c|c|c|c|c|c|c|}
\hline & $\begin{array}{c}(1) \\
\text { applications } \\
\text { per } 10 \text { people }\end{array}$ & $\begin{array}{c}(2) \\
\text { applications } \\
\text { per } 10 \text { people }\end{array}$ & $\begin{array}{c}(3) \\
\text { awards } \\
\text { per } 10 \text { people }\end{array}$ & $\begin{array}{c}\text { (4) } \\
\text { awards } \\
\text { per } 10 \text { people }\end{array}$ & $\begin{array}{c}\text { (5) } \\
\text { awards/ } \\
\text { determinations }\end{array}$ & $\begin{array}{c}\text { (6) } \\
\text { awards/ } \\
\text { determinations }\end{array}$ \\
\hline $\begin{array}{l}\text { unemployment } \\
\text { rate }\end{array}$ & $\begin{array}{l}0.522^{* *} \\
(0.208)\end{array}$ & $\begin{array}{l}0.364^{* * *} \\
(0.0999)\end{array}$ & $\begin{array}{l}-0.0161 \\
(0.0867)\end{array}$ & $\begin{array}{l}-0.0238 \\
(0.0673)\end{array}$ & $\begin{array}{c}-0.922^{* * *} \\
(0.324)\end{array}$ & $\begin{array}{c}-0.401 \\
(0.257)\end{array}$ \\
\hline state FE & No & Yes & No & Yes & No & Yes \\
\hline $\mathrm{N}$ & 561 & 561 & 561 & 561 & 561 & 561 \\
\hline R-squared & 0.558 & 0.953 & 0.479 & 0.891 & 0.400 & 0.851 \\
\hline
\end{tabular}




\title{
Appendix
}

\author{
Table A1
}

Outcome measures by population, beginning and end of $1990 \mathrm{~s}$

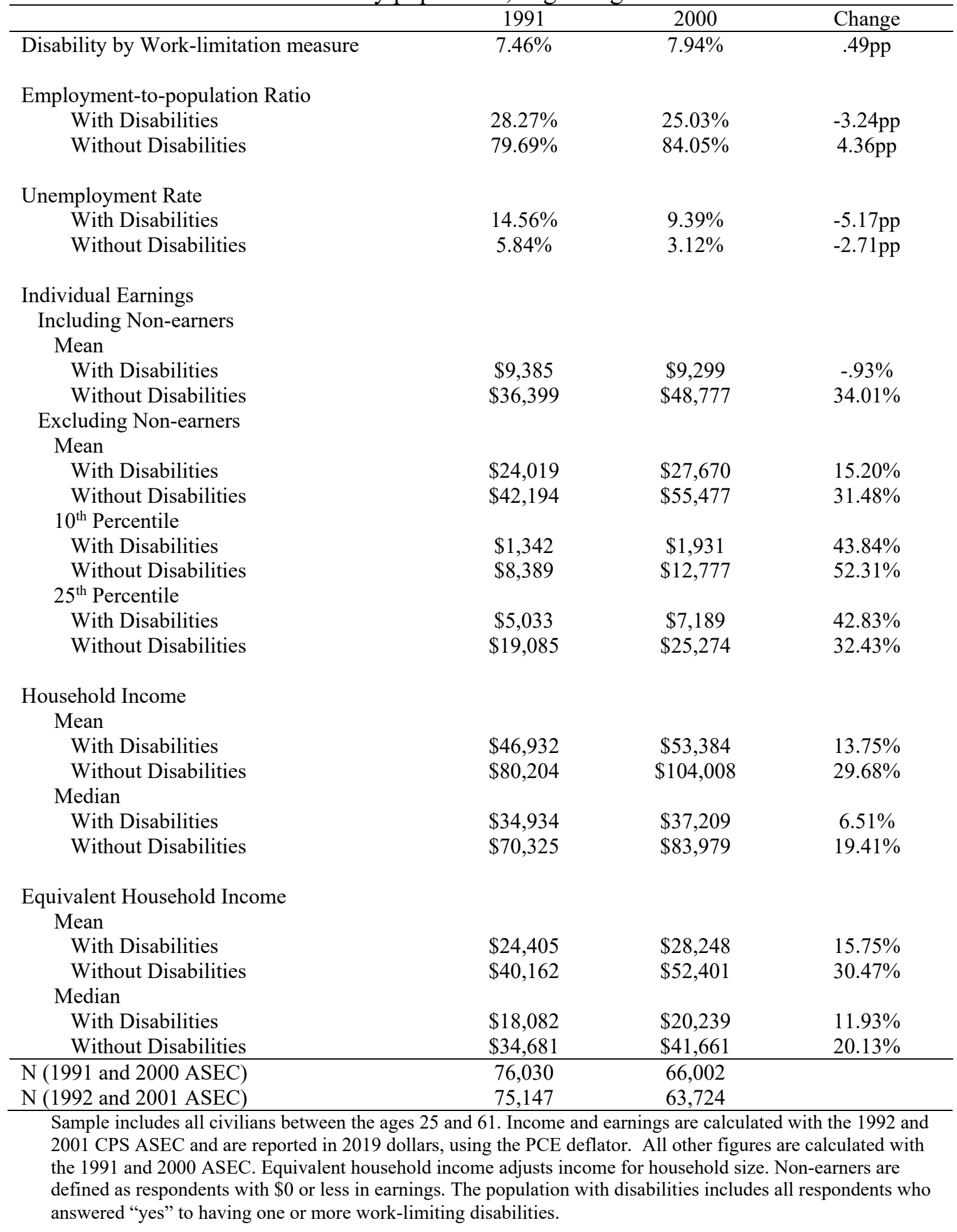


Table A2: Regression results for disability program applications/awards

Main Results, Recovery from 2001 Recession

\begin{tabular}{|c|c|c|c|c|c|c|}
\hline & $\begin{array}{c}(1) \\
\text { applications } \\
\text { per } 10 \text { people }\end{array}$ & $\begin{array}{c}(2) \\
\text { applications } \\
\text { per } 10 \text { people }\end{array}$ & $\begin{array}{c}(3) \\
\text { awards } \\
\text { per } 10 \text { people }\end{array}$ & $\begin{array}{c}(4) \\
\text { awards } \\
\text { per } 10 \text { people }\end{array}$ & $\begin{array}{c}(5) \\
\text { awards/ } \\
\text { determinations }\end{array}$ & $\begin{array}{c}(6) \\
\text { awards / } \\
\text { determinations }\end{array}$ \\
\hline $\begin{array}{l}\text { unemployment } \\
\text { rate }\end{array}$ & $\begin{array}{l}1.434^{* * *} \\
(0.298)\end{array}$ & $\begin{array}{l}0.410^{* *} \\
(0.172)\end{array}$ & $\begin{array}{l}0.287^{* *} \\
(0.127)\end{array}$ & $\begin{array}{c}-0.119 \\
(0.0805)\end{array}$ & $\begin{array}{l}-1.498^{*} \\
(0.800)\end{array}$ & $\begin{array}{c}-1.817^{* * *} \\
(0.587)\end{array}$ \\
\hline $\begin{array}{l}\text { state FE } \\
\mathrm{N} \\
\mathrm{R} \text {-squared }\end{array}$ & $\begin{array}{c}\text { No } \\
306 \\
0.655\end{array}$ & $\begin{array}{c}\text { Yes } \\
306 \\
0.972\end{array}$ & $\begin{array}{c}\text { No } \\
306 \\
0.248\end{array}$ & $\begin{array}{c}\text { Yes } \\
306 \\
0.914\end{array}$ & $\begin{array}{c}\text { No } \\
306 \\
0.166\end{array}$ & $\begin{array}{c}\text { Yes } \\
306 \\
0.909\end{array}$ \\
\hline
\end{tabular}

